The INL is a

U.S. Department of Energy

National Laboratory

operated by

Battelle Energy Alliance

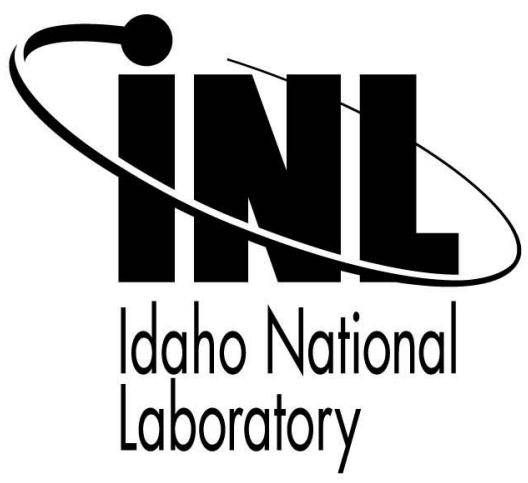

\title{
Parametric Study of
} Large-Scale Production of Syngas Via High Temperature CoElectrolysis

\section{AlChE Annual Meeting}

\author{
J. E. O'Brien \\ M. G. McKellar \\ C. M. Stoots \\ J. S. Herring \\ G. L. Hawkes
}

\section{November 2007}

This is a preprint of a paper intended for publication in a journal or proceedings. Since changes may be made before publication, this preprint should not be cited or reproduced without permission of the author. This document was prepared as an account of work sponsored by an agency of the United States Government. Neither the United States Government nor any agency thereof, or any of their employees, makes any warranty, expressed or implied, or assumes any legal liability or responsibility for any third party's use, or the results of such use, of any information, apparatus, product or process disclosed in this report, or represents that its use by such third party would not infringe privately owned rights. The views expressed in this paper are not necessarily those of the United States Government or the sponsoring agency. 


\title{
PARAMETRIC STUDY OF LARGE-SCALE PRODUCTION OF SYNGAS VIA HIGH TEMPERATURE CO-ELECTROLYSIS
}

\author{
J. E. O’Brien, M. G. McKellar, C. M. Stoots, J. S. Herring and G. L. Hawkes \\ Idaho National Laboratory \\ Idaho Falls, ID 83415, USA
}

\section{ABSTRACT}

A process model has been developed to evaluate the potential performance of a largescale high-temperature co-electrolysis plant for the production of syngas from steam and carbon dioxide. The co-electrolysis process allows for direct electrochemical reduction of the steam - carbon dioxide gas mixture, yielding hydrogen and carbon monoxide, or syngas. The process model has been developed using the Honeywell UniSim systems analysis code. Using this code, a detailed process flow sheet has been defined that includes all the components that would be present in an actual plant such as pumps, compressors, heat exchangers, turbines, and the electrolyzer. Since the electrolyzer is not a standard UniSim component, a custom one-dimensional co-electrolysis model was developed for incorporation into the overall UniSim process flow sheet. The one dimensional co-electrolysis model assumes local chemical equilibrium among the four process-gas species via the gas shift reaction. The electrolyzer model allows for the determination of co-electrolysis outlet temperature, composition (anode and cathode sides); mean Nernst potential, operating voltage and electrolyzer power based on specified inlet gas flow rates, heat loss or gain, current density, and cell area-specific resistance. The one-dimensional electrolyzer model was validated by comparison with results obtained from a fully three dimensional computational fluid dynamics model developed using FLUENT, and by comparison to experimental data. This paper provides representative results obtained from the UniSim flow sheet model for a 300 MW co-electrolysis plant, coupled to a high-temperature gas-cooled nuclear reactor. The coelectrolysis process, coupled to a nuclear reactor, provides a means of recycling carbon dioxide back into a useful liquid fuel. If the carbon dioxide source is based on biomass, the overall process, from production through utilization, would be climate neutral.

\section{NOMENCLATURE}

$\begin{array}{ll}A_{\text {cell }} & \text { electrolysis cell active area, } \mathrm{cm}^{2} \\ A S R & \text { area-specific resistance, } \mathrm{Ohm} \cdot \mathrm{cm}^{2} \\ F & \text { Faraday number, } 96487 \mathrm{C} / \mathrm{mol} \\ I_{e} & \text { total ionic current, Ampere } \\ i & \text { current density, Ampere/cm } \\ L H V_{i} & \text { lower heating value of component } \mathrm{i}, \mathrm{J} / \mathrm{mol} \\ \dot{N}_{i} & \text { molar flow rate of component } \mathrm{i}, \mathrm{mol} / \mathrm{s} \\ N_{\text {cells }} & \text { number of cells in electrolysis stack } \\ \dot{Q} & \text { heat transfer rate, } \mathrm{W} \\ T & \text { temperature, } \mathrm{K} \\ \eta_{\text {syn }} & \text { overall thermal-to-syngas process efficiency }\end{array}$




\section{INTRODUCTION}

Large-scale production of synthetic liquid fuels represents one possible path toward greater energy independence. Primary advantages of synthetic liquid fuels, as compared to hydrogen, are that the infrastructure for liquid fuel distribution is already in place and on-board-vehicle storage is not an issue. However, these fuels will release carbon dioxide to the atmosphere when burned. Therefore, climate-neutral methods of synfuel production are most desirable. If the energy input to the synfuel production process is based on nuclear energy, and if the carbon source is based on biomass, a large-scale climate-neutral synthetic fuel production strategy could be achieved. Nuclear-powered high-temperature electrolysis of steam and carbon dioxide to produce syngas, with subsequent Fisher-Tropsch conversion to liquid fuel represents such a strategy.

This research is an outgrowth of ongoing work at the Idaho National Laboratory (INL), on high-temperature steam electrolysis for hydrogen production [1], funded by the US Department of Energy under the Nuclear Hydrogen Initiative. High-temperature electrolysis (HTE) is one of two technologies under evaluation for large-scale hydrogen production based on nuclear energy. Advanced high-temperature nuclear reactors have the potential to enable efficient, large-scale, carbon-free hydrogen production [2]. Large-scale nuclear hydrogen production based on water-splitting is already under serious consideration in the short term to supply hydrogen for upgrading of low-quality petroleum resources such as the Athabasca Oil Sands [3]. In the intermediate term, large-scale hydrogen production will be required for the production of synthetic liquid hydrocarbon fuels. In the long term, large-scale hydrogen production may fuel the hydrogen economy.

High-temperature electrolysis is based on solid oxide fuel cell (SOFC) technology and materials. The zirconia electrolytes used for SOFCs conduct oxygen ions, so they can be used to electrolyze steam $\left(\mathrm{H}_{2} \mathrm{O}\right)$ to hydrogen $\left(\mathrm{H}_{2}\right)$, and/or carbon dioxide $\left(\mathrm{CO}_{2}\right)$ to carbon monoxide (CO). When both steam and carbon dioxide are present simultaneously in the feed stream, the total amounts of hydrogen and carbon monoxide that are produced depend on the electrolysis current. The relative amount of hydrogen produced versus carbon monoxide is determined by the relative amounts of steam, hydrogen (included in the feed stream as a reducing agent) and carbon dioxide included in the feed stream and by the effect of the gas shift reaction:

$$
\mathrm{CO}_{2}+\mathrm{H}_{2}<=>\mathrm{H}_{2} \mathrm{O}+\mathrm{CO}
$$

The desired molar ratio of hydrogen to carbon monoxide in the gaseous product depends on the particular liquid fuel to be produced as a final product, but a 2-to-1 ratio of $\mathrm{H}_{2}$ to $\mathrm{CO}$ is typical.

In order to evaluate the potential syngas-production performance of large-scale hightemperature co-electrolysis operations, we have developed an engineering process model at INL using the commercial system-analysis code UniSim. Using this code, several detailed process flow sheets have been defined that include all of the components that would be present in an actual high-temperature co-electrolysis (HTCE) plant such as pumps, compressors, heat exchangers, turbines, and the electrolyzer. However, since the actual electrolyzer is not a standard UniSim component, custom one-dimensional co-electrolysis models have been developed for both steam [4, 5] and steam $/ \mathrm{CO}_{2}$ electrolysis for incorporation into the overall process flow sheet. Details of this one-dimensional coelectrolysis electrolyzer model were provided in [5]. This paper will provide details of an overall 
co-electrolysis system process model, with representative results, over a range of operating conditions. Results of similar process simulations for pure steam electrolysis were provided in reference [6].

\section{PROCESS DESCRIPTION}

A graphical representation of the process model developed for this study is presented in Fig. 1. The primary process feedstock streams are liquid water and carbon dioxide. The inlet water stream is compressed in the liquid phase to the process operating pressure of $3.5 \mathrm{MPa}$ using a pump. This operating pressure was selected because it is approximately equal to the desired operating pressure for a Fisher-Tropsch process using a cobalt catalyst. Downstream of the pump, condensate from the water knockout tank is recycled back into the inlet stream at M3. The water stream is then vaporized and pre-heated in the electrolysis recuperator, which recovers heat from the post-electrolyzer process and sweep-gas outlet streams. Downstream of the recuperator, at $\mathrm{M} 2$, the steam is mixed with carbon dioxide plus recycled hydrogen and carbon monoxide product gas. A fraction of the product gas is recycled in this way in order to assure that reducing conditions are maintained on the steam/hydrogen electrode.

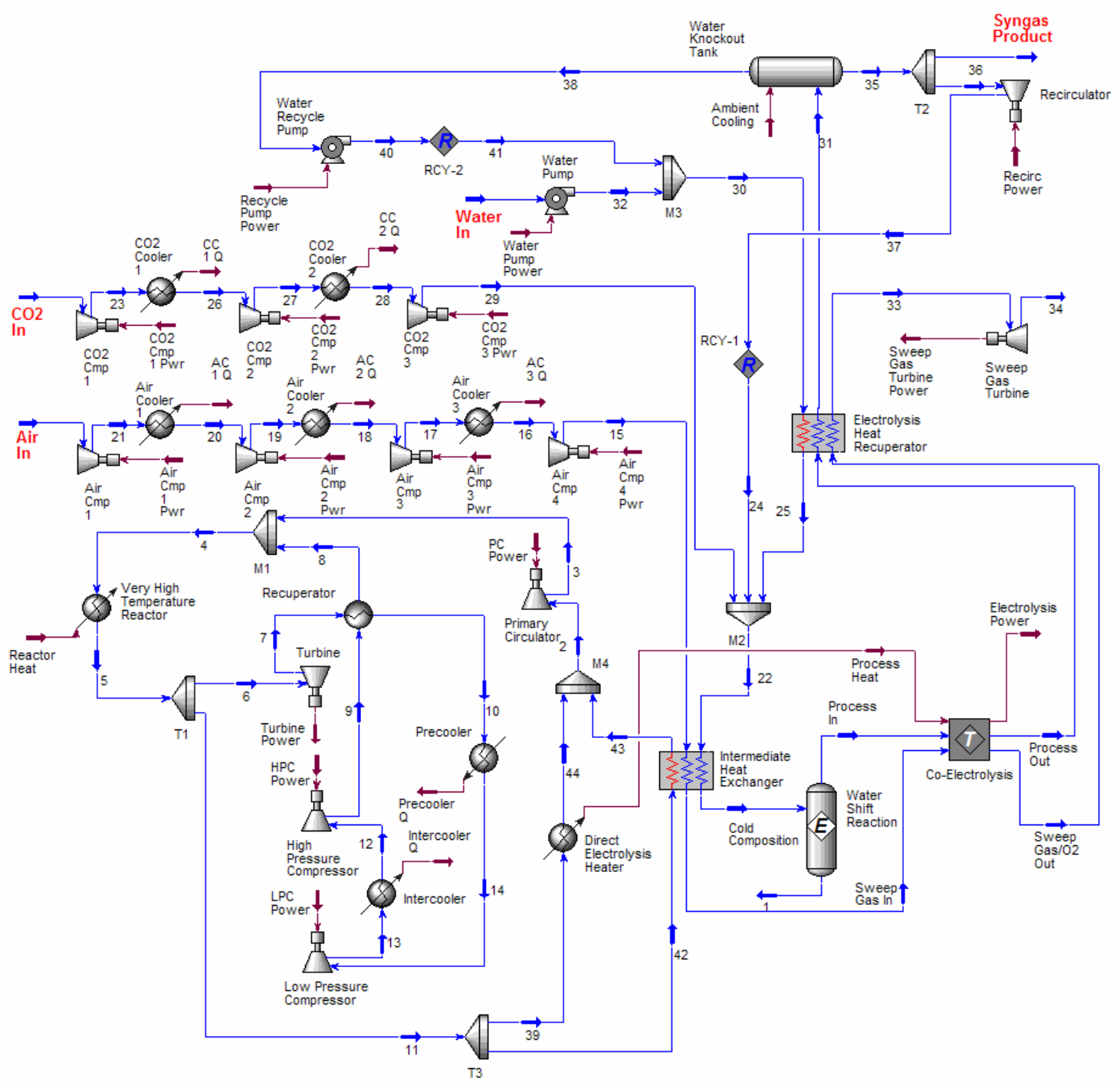

Figure 1. Process flow diagram for co-electrolysis plant. 
Downstream of the mixer, the process gas mixture enters the intermediate heat exchanger (IHX), where final heating to the electrolysis operating temperature occurs, using hightemperature process heat from the nuclear reactor. A gas shift reaction occurs with heated gas mixture represented by an equilibrium reactor in the process flow diagram, allowing chemical equilibrium to be achieved. The process stream then enters the electrolyzer, where oxygen is electrolytically removed from the system, producing hydrogen and carbon monoxide.

The UniSim version of the co-electrolysis model utilizes built-in features of UniSim as much as possible. UniSim inherently ensures mass and energy balances across all components, includes thermodynamic data for all chemical species, calculates chemical equilibrium states for the gas shift reaction, and calculates the heats of reaction for $\mathrm{CO}_{2}$ and $\mathrm{H}_{2} \mathrm{O}$ electrolysis. The rate of electrolytic oxygen removal from the process stream, the mean Nernst potential and the electrolyzer operating voltage are calculated by means of an embedded spreadsheet. An expanded process flow diagram of the electrolyzer module is shown in Fig. 2. This diagram represents the UniSim implementation of the one-dimensional chemical equilibrium coelectrolysis model discussed in detail in [5]. Within this module, the hot shifted process stream enters a conversion reactor where the steam and/or carbon dioxide are electrolytically reduced. The conversion reactor unit includes both the steam and carbon dioxide reduction reactions. Based on the percent conversion of the steam and $\mathrm{CO}_{2}$, the reactor will calculate the associated heat of reaction. The percent conversion of steam and/or $\mathrm{CO}_{2}$ is determined by the total electrolysis current, which is the product of the current and the number of cells. The molar oxygen removal rate is therefore given by Faraday's law:

$$
\Delta \dot{N}_{O}=\frac{I_{e}}{2 F} ; \text { where } I_{e}=i A_{\text {cell }} N_{\text {cells }}
$$

To avoid oxygen starvation, the minimum required inlet steam and $\mathrm{CO}_{2}$ molar flow rates must satisfy the following constraint:

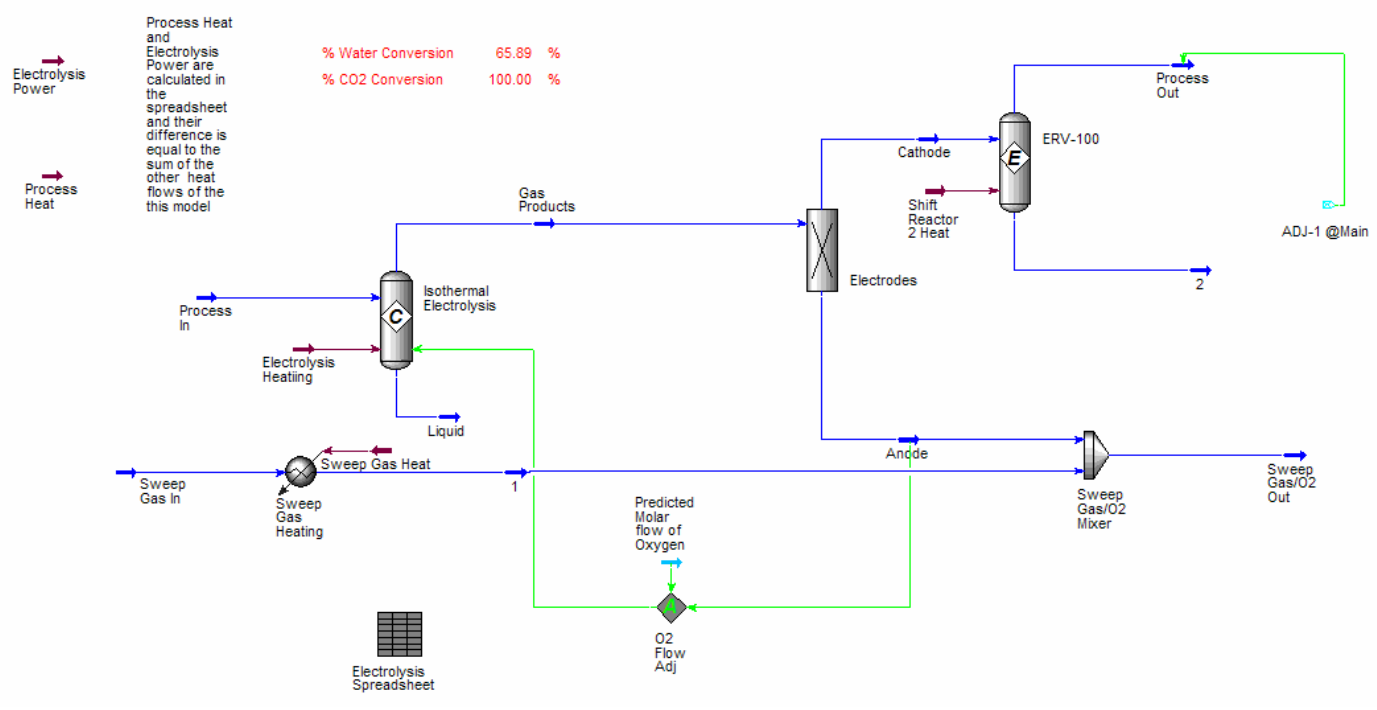

Figure 2. Process flow diagram for the electrolysis module within UniSim. 


$$
\dot{N}_{\mathrm{H}_{2} \mathrm{O}}+\dot{N}_{\mathrm{CO}_{2}} \geq \frac{I_{e}}{2 F}
$$

Note that the oxygen contribution from the $\mathrm{CO}_{2}$ is only counted once, since we want to avoid creation of carbon soot, which could foul the cells.

This value of the molar flow rate of produced oxygen is stored in a dummy stream. A logical adjust is used to change the percent conversion of steam and carbon dioxide until the oxygen molar flow rate leaving the conversion reactor is the same as the calculated value. The oxygen is split from the rest of the reacted process-gas components by means of a component splitter unit (labeled Electrodes). The split oxygen combines with the sweep gas. The remaining components are passed through a second equilibrium gas shift reactor to determine the outlet equilibrium composition.

The UniSim implementation of the one-dimensional chemical equilibrium co-electrolysis (CEC) model was validated by comparison with an analytical version that was implemented in MathCad and with a full three-dimensional (3-D) computational fluid dynamic (CFD) model developed using FLUENT. Representative results are presented in Fig. 3. A more comprehensive comparison is provided in reference [5]. Electrolyzer-outlet mole fractions of the four process-gas species are presented in Fig. 3 (a) as a function of current density for the per-cell inlet molar flow rates, inlet temperature, area-specific resistance, and thermal boundary condition indicated in the figure. The cold inlet mole fractions corresponding to the indicated molar flow rates are also plotted in the figure for each species. Outlet mole fraction results obtained from the MathCad and UniSim implementations of the CEC are plotted, along with results obtained from a 3-D CFD co-electrolysis simulation obtained using FLUENT. Details of the FLUENT co-electrolysis model are provided in reference [7]. The FLUENT model includes reaction kinetics via separate forward and backward reaction rate constants for the shift reaction. Outlet mole fraction predictions based on the three independent methods are virtually identical. Mole fractions of steam and carbon dioxide decrease with current density, while the mole fractions of hydrogen and carbon monoxide increase. For the inlet

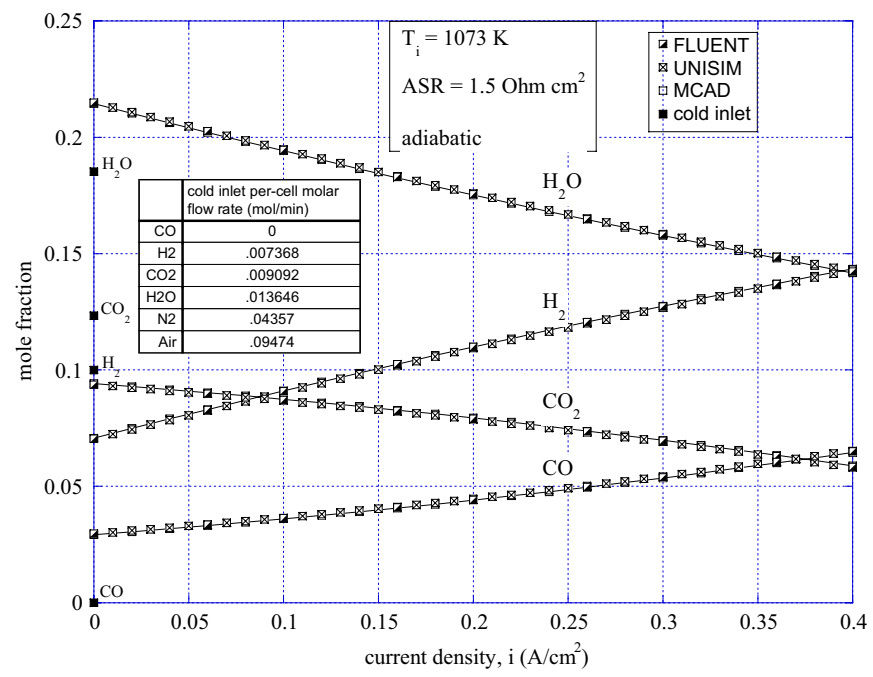

(a)

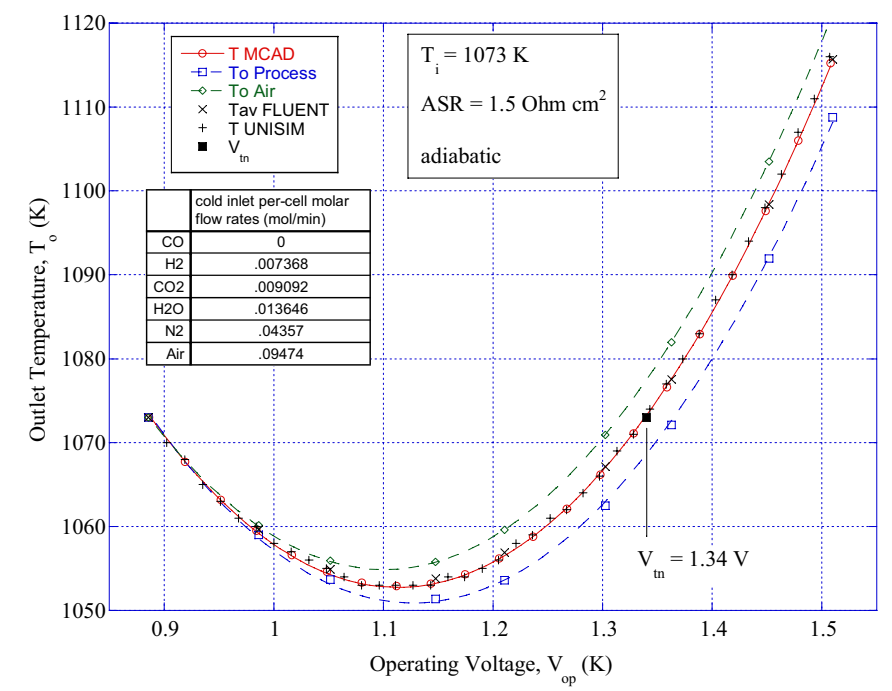

(b)

Figure 3. Electrolyzer model results and comparisons, (a) Variation of species mole fraction as a function of current density; (b) Electrolyzer outlet temperature as a function of operating voltage. 
composition chosen for this particular run, the ratio of produced hydrogen to carbon monoxide is slightly higher than 2-to-1.

Electrolyzer outlet temperature predictions from the CEC and FLUENT models are presented in Fig. 3 (b) for the same conditions as the results presented in Fig. 3 (a). For low values of operating voltage (and current density), outlet gas temperatures for adiabatic operation are lower than the inlet temperature. The magnitude of this adiabatic temperature depression is dependent on the voltage and the flow rates of the process gases and sweep gas. For operating voltages higher than the thermal neutral voltage $(1.34 \mathrm{~V}$ in this case), the gas outlet temperatures are higher than the inlet temperature due to the dominance of ohmic heating. The figure shows predictions from the MathCad and UniSim versions of the CEC model as well as predictions from the FLUENT model. The 3-D FLUENT model simulates a single electrolysis cell as it would exist in a planar stack, with a cross-flow arrangement of process and sweep gases. Consequently, the average process-gas and sweep-gas outlet temperatures are not necessarily the same. For this particular case, the outlet temperature of the air sweep was higher than the outlet temperature of the process gas, as shown in the figure. An overall heat-capacity-rate-weighted mean outlet gas temperature was also calculated based on the process-gas and sweep-gas flow rates and temperatures. This result is also shown in Fig. 3 (b). The weighted mean outlet temperature agrees very well with predictions obtained from the CEC model.

Returning to Fig. 1, downstream of the electrolyzer, the hydrogen and carbon monoxide rich product stream flows through the electrolysis recuperator where the product stream is cooled and the inlet process stream is preheated. The cooled product stream is split at T2 and a fraction of the product gas is recycled into the inlet process stream, as discussed previously. A recirculating blower is required to repressurize the recycle stream to the upstream pressure at M2. The remainder of the product stream is cooled further at the water knockout tank, where the majority of any residual steam is condensed and separated, yielding dry syngas product.

The process flow diagram shows air in use as a sweep gas, to remove the excess oxygen that is evolved on the anode side of the electrolyzer. For the air-sweep cases, inlet air is compressed to the system operating pressure of $3.5 \mathrm{MPa}$ in a four-stage compressor with intercooling. The final compression stage is not followed by a cooler, so the air enters the IHX at about $105^{\circ} \mathrm{C}$. The sweep gas is heated to the electrolyzer operating temperature of $800^{\circ} \mathrm{C}$ via the IHX which supplies high-temperature nuclear process heat directly to the system. The sweep gas then enters the electrolyzer, where it is combined with product oxygen. Finally, it passes through the electrolysis recuperator to help preheat the incoming process gas. Some of the sweep gas compression work is recovered using a sweep-gas turbine located at the sweep-gas exit.

In order to avoid the work requirement associated with compression of the sweep gas, it is possible to operate with no sweep gas, and to allow the system to produce pure oxygen, which could potentially be supplied to another collocated process such as an oxygen-blown gasifier. For this mode of operation, the four-stage air compressor would not be included in the process flow diagram and there would be no air flow through the intermediate heat exchanger. Oxygen would simply be evolved from the anode side of the electrolyzer at the electrolysis operating pressure and temperature. It would flow through the electrolysis heat recuperator and the outlet turbine. The results of the system analysis will show that this concept is desirable from 
the standpoint of overall process efficiency, but there are significant technical issues associated with handling high-temperature pure oxygen that would have to be addressed.

The final portion of the process flow diagram in the lower left represents the high temperature gas reactor power cycle and nuclear process heat supply. The reactor is assumed to have a capacity of $600 \mathrm{MW}$ thermal. The outer flow loop downstream of splitter T1 supplies high-temperature nuclear process heat to the IHX. The remainder of the hightemperature gas flows through a recuperated Brayton cycle. The cycle includes a gas turbine, recuperator, and two-stage compressor with intercooling. For the baseline case, the reactor inlet and outlet temperatures were assumed to be 490 and $900^{\circ} \mathrm{C}$, respectively, consistent with the direct Brayton cycle concept proposed by General Atomics [8]. The turbine inlet pressure is $7 \mathrm{MPa}$. A $20^{\circ} \mathrm{C}$ temperature difference was assumed across the recuperator. The thermal efficiency of this baseline power cycle is $48.3 \%$.

Two sets of system simulations were performed. The first set examined the overall syngas production efficiency variation as a function of current density for two ASR values and for both isothermal and adiabatic electrolyzer operation. The second set examined the variation in system performance as a function of reactor outlet temperature.

The methodology followed in performing the first set of system simulations will now be discussed. To assure that the results generated by the model were consistent for all cases, the following constraints were imposed:

- The sum of the inlet hydrogen and carbon monoxide mole fractions before electrolysis and before any water shift reaction was set to 0.1 by adjusting the fraction of syngas product recycled back to the electrolysis process.

- The sum of the electrolysis outlet hydrogen and carbon monoxide mole fractions was maintained at 0.9 by adjusting the total mass flow rate of the process gas into the electrolysis process as the current density was varied. This is a fixed oxygen utilization condition.

- For the air-sweep cases, the oxygen mole fraction exiting the electrolysis process on the air side was fixed at 0.5 by adjusting the inlet air flow rate as the current density was varied. Obviously, for the no-sweep cases, the air flow was zero and the outlet oxygen mole fraction was 1.0 .

- The ratio of hydrogen to carbon dioxide in the product stream was fixed at 2.12 by adjusting the carbon dioxide inlet flow rate. This ratio is optimal for the production of synthetic fuel using a Fischer Tropsch process with a cobalt catalyst.

- The minimum approach temperature of the Electrolysis Heat Recuperator was set at $50^{\circ} \mathrm{C}$ by adjusting the flow split between the power cycle and the intermediate heat exchanger.

- The temperatures of the helium entering and exiting the reactor were fixed at $490^{\circ} \mathrm{C}$ and $900^{\circ} \mathrm{C}$ respectively.

- The overall heat transfer coefficient and heat exchanger area product (UA) was kept constant for the recuperator of the Brayton power cycle.

Power generated by the direct Brayton cycle was supplied to the high temperature electrolysis process and its support equipment. For each case, care was taken to ensure that the net power remaining (the power from the power cycle not used for electrolysis) was positive.

The per-cell active area for electrolysis was assumed to be $225 \mathrm{~cm}^{2}$ for all cases considered in this study. This cell size is well within the limits of current technology for planar 
cells. The total number of cells used in the process simulations was determined by specifying a maximum current density for each $A S R$ value considered that was large enough to ensure that the operating voltage would just exceed the thermal neutral voltage. For the higher $A S R$ value of $1.25 \mathrm{Ohm} \cdot \mathrm{cm}^{2}$, the maximum current density was set at $0.25 \mathrm{~A} / \mathrm{cm}^{2}$ and an adiabatic thermal boundary condition was assumed. The total number of cells for this base case was adjusted until the total remaining power was zero. In other words, the full power cycle output at this operating point is dedicated to electrolysis. At lower current densities, the power cycle output exceeds the value required for electrolysis and this excess power would be supplied to the grid. For the case of $A S R=0.25 \mathrm{Ohm} \cdot \mathrm{cm}^{2}$, the maximum current density was set at 1.0 $\mathrm{A} / \mathrm{cm}^{2}$. A much higher maximum current density was required for the lower ASR case, again in order to assure that the thermal neutral voltage was just exceeded. This procedure resulted in $3.488 \times 10^{6}$ cells required for the high-ASR cases and $8.733 \times 10^{5}$ required for the low- $A S R$ cases. Obviously, for specified target hydrogen production rate, a low ASR value is desirable from the standpoint of capital cost.

For the isothermal cases, heat from the reactor was directly supplied to the electrolysis process to maintain isothermal conditions. This heat exchange was parallel to the heat exchange process via the intermediate heat exchanger. For the adiabatic cases, the direct electrolyzer heater was not used.

System simulations were also performed to examine the effect of reactor outlet temperature on overall syngas production performance. As the reactor outlet temperature is varied, both the power cycle and the electrolysis processes are directly affected. Lower reactor outlet temperatures result in lower power-generation efficiencies, and poorer electrolyzer performance.

The variable reactor-outlet-temperature simulations were constrained similarly, with the following exceptions:

- The number of electrolysis cells was adjusted for each case until the total electric power remaining is less than $50 \mathrm{~kW}$. In other words, the plant is totally dedicated to hydrogen production.

- The co-electrolysis process was run at the thermal neutral voltage, such that the electrolyzer outlet gas temperatures for each case were the same as the electrolyzer inlet temperatures. This constraint required adjustment of the current density until the thermal neutral condition was met.

- The cases for which the exiting temperature of the reactor coolant stream are $850^{\circ} \mathrm{C}$ or less, the electrolyzer was operated at $800^{\circ} \mathrm{C}$. For reactor outlet temperatures of $800^{\circ} \mathrm{C}$ or less, two auxiliary electrical heaters (one on the process stream and one on the air stream) were used to maintain the $800^{\circ} \mathrm{C}$ electrolyzer operating temperature. The power for these heaters is supplied by the power cycle and is accounted for in the syngas production efficiency.

An important performance parameter for all of the cases studied is the overall thermal-tosyngas process efficiency, defined as follows:

$$
\eta_{s y n}=\frac{\dot{N}_{\mathrm{H}_{2}} L H V_{\mathrm{H}_{2}}+\dot{N}_{C O} L H V_{C O}}{\sum_{i} \dot{Q}_{i}}
$$


This efficiency definition quantifies the ratio of the low heating value of the produced syngas to the total thermal energy required to produce it. This total thermal energy includes direct process heat inputs such as at the IHX and at the electrolyzer (isothermal cases). In addition, the thermal equivalent of any power-consuming devices such as pumps and compressors, electrical heaters, etc. in the system must be accounted. The thermal equivalent of the power-consuming devices is given by the power requirement divided by the thermal efficiency of the power cycle.

The $A S R$ value used in the electrolyzer module is temperature-dependent per the following Arrhenius equation:

$$
A S R(T)=A S R_{1100 K}-0.463+3.973 \times 10^{-5} \exp \left(\frac{10300}{T(K)}\right)(5)
$$

where $A S R_{1100 \mathrm{~K}}$ represents the userspecified cell ASR at the temperature 1100 $\mathrm{K}$. This constant allows one to shift the entire $A S R$ curve to higher or lower $A S R$ values, to mimic lower or higher performing cells, respectively. This equation for $A S R(T)$ is based on empirical data obtained from an actual operating stack, modified to allow user specification of the $A S R$ value at 1100 $\mathrm{K}$. In order to show the trends that can be expected with higher or lower $A S R$, two values of $A S R_{1100 K}$ have been included in this study. The $A S R_{1100 K}$ value of 1.25 represents a stack-average $A S R$ value at $1100 \mathrm{~K}$ that should be achievable in the short term with existing technology. The $A S R_{1100 \mathrm{~K}}$ value of 0.25 is an optimistic value that has been observed in button cells, but will be difficult to achieve in a stack in the short term. The temperature dependence of the $A S R$ is important for the adiabatic cases (since the outlet temperature in these cases is generally different than the inlet temperature) and for evaluating the effect of electrolyzer inlet temperature on overall process efficiency.

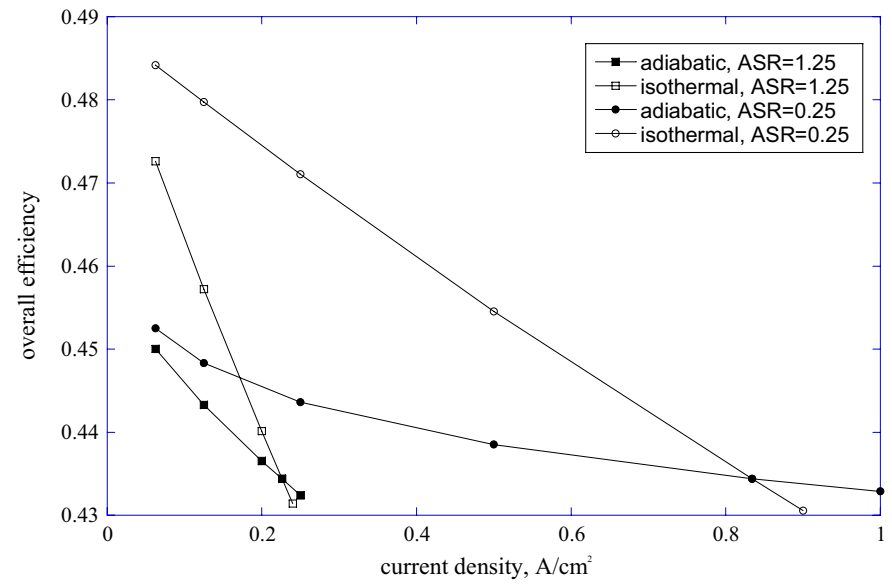

(a)

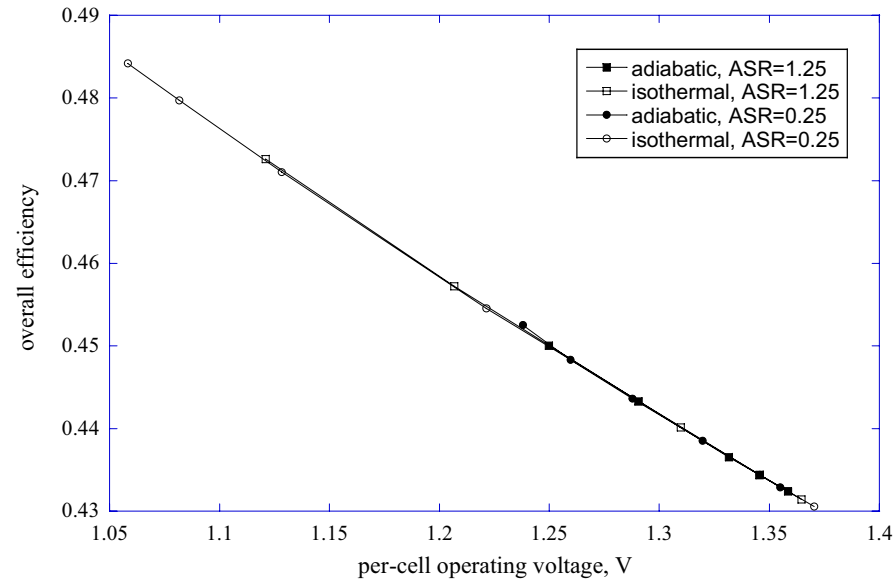

(b)

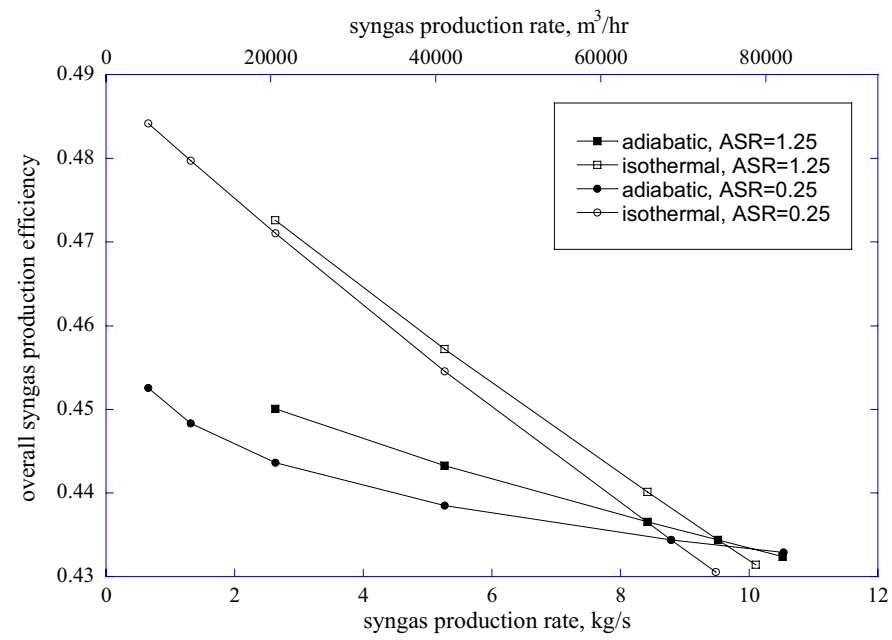

(c)

Figure 4. Overall syngas production efficiencies for the air-sweep cases plotted as a function of current density (a), per-cell operating voltage (b), and syngas production rate (c). 


\section{RESULTS}

Representative overall syngas production efficiency results corresponding to the process flow diagram of Fig. 1, for the fixedutilization operating conditions described above, with air sweep, are presented in Fig. 4. Overall efficiencies are plotted against current density in Fig. 4(a), against per-cell operating voltage in Fig. 4(b), and against syngas production rate in Fig. 4(c). Results of four cases are presented: low and high $A S R$, adiabatic and isothermal electrolyzer operation. Predicted overall thermal-tosyngas efficiency values are generally within 5 percentage points of the power-cycle efficiency of $48.3 \%$. Fig. 4(a) indicates a relatively rapid decrease in overall efficiency for the high-ASR cases as current density is increased. Note also that the maximum current density for the high-ASR cases is limited to about $0.25 \mathrm{~A} / \mathrm{cm}^{2}$. This limit necessitates deployment of many more electrolyzer cells in order to consume the available power. Electrolyzer efficiency is inversely proportional to operating voltage. Higher current densities, and correspondingly higher syngas production rates require higher operating voltages. Therefore, overall efficiencies decrease with increasing current density. The adiabatic cases show a nonlinear decrease in overall efficiency with increasing current density, as a result of the temperature-dependent $A S R$ used in the simulation. For isothermal cases, the $A S R$ is constant and the overall efficiencies decrease linearly with current density. For a specified current density (and syngas production rate), the isothermal cases produce higher efficiencies, at operating voltages below thermal neutral.

Interestingly, the overall process efficiencies collapse onto a single line when plotted as a function of per-cell operating voltage, as shown in Fig. 4(b). Note that the highest operating voltages shown are just above the thermal neutral voltage of $1.34 \mathrm{~V}$. Note also that the highest overall efficiency

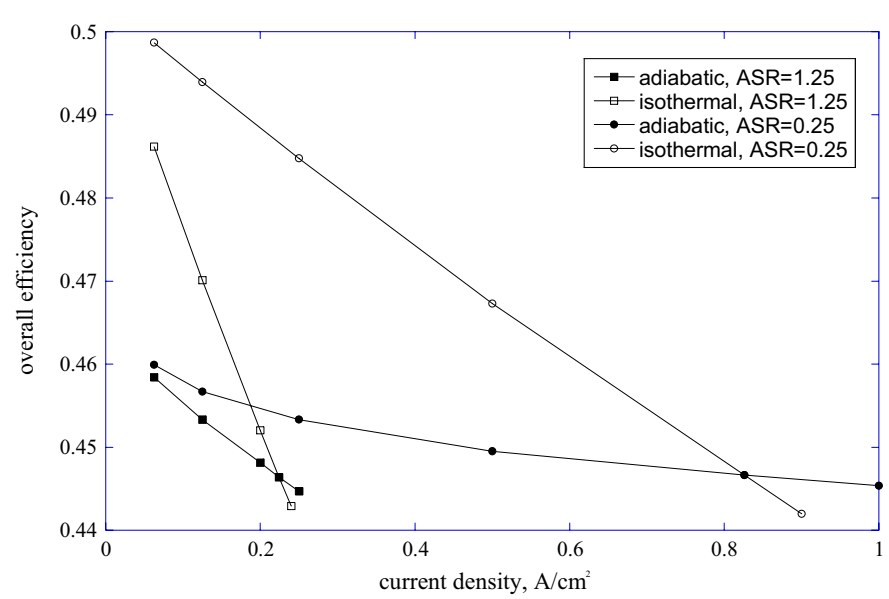

(a)

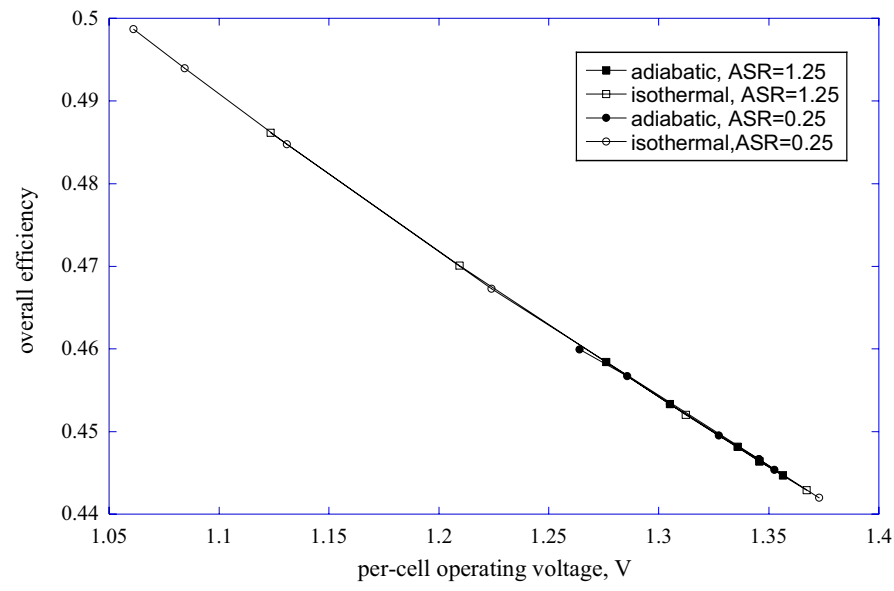

(b)

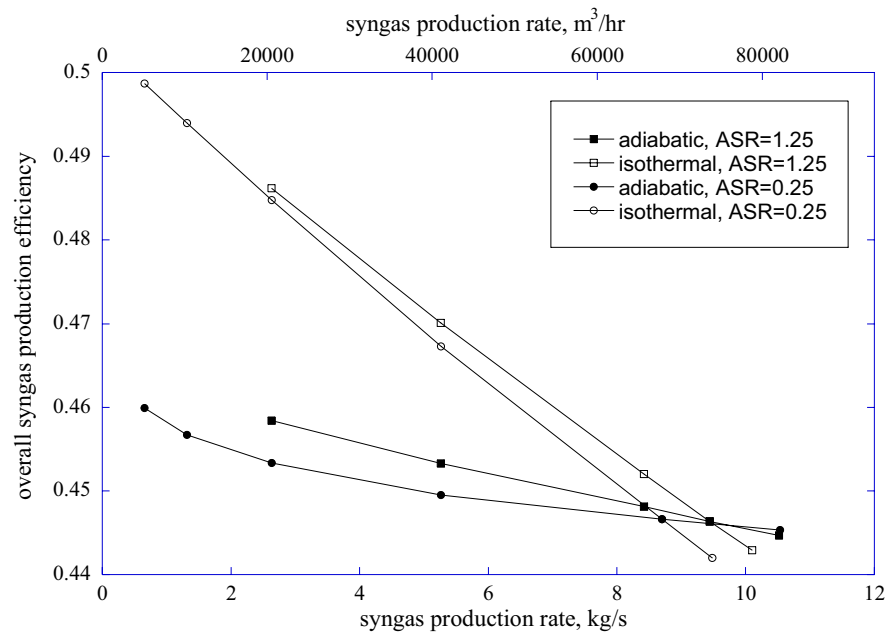

(c)

Figure 5. Overall syngas production efficiencies for the no-sweep cases plotted as a function of current density (a), per-cell operating voltage (b), and syngas production rate (c). 
plotted in Fig. 4 (for ASR $=0.25$, isothermal, $\mathrm{i}=0.0625 \mathrm{~A} / \mathrm{cm}^{2}$ ) is actually slightly higher than the power cycle efficiency of $48.3 \%$.

Fig. 4(c) shows that syngas production rates in excess of $10 \mathrm{~kg} / \mathrm{s}(78,000 \mathrm{SCMH})$ could be achieved with a dedicated $600 \mathrm{MW}_{\text {th }}$ syngas-production plant. Fig. 4(c) also indicates similar overall efficiencies for the low-ASR and high-ASR cases at a specified electrolyzer thermal operating condition (adiabatic or isothermal) and syngas production rate. Recall, however, that the high-ASR plant requires four times as many cells as the low-ASR plant for the same syngas production rate. So the capital cost of the electrolytic plant would be significantly greater with the high- $A S R$ cells compared to the low- $A S R$ cells.

The results shown in Fig. 4 are qualitatively similar to results presented in reference [6] for pure steam electrolysis. However, the coelectrolysis results presented here have overall efficiencies values that are a few percentage points higher. The primary reason is that the modeled and predicted power cycle efficiency for the present study is higher (48.3\%) than the assumed (not modeled) power cycle efficiency of $45 \%$ used for the pure steam electrolysis study. In addition, the operating pressure for this plant was chosen to be $3.5 \mathrm{MPa}$ rather than $5 \mathrm{MPa}$ used in the previous study of pure steam electrolysis. Overall plant efficiencies decrease slightly with increasing operating pressure.

Since the electrolysis cells produce oxygen, rather than consuming it as in the fuel-cell mode, a sweep gas stream is not necessarily required. There has been some discussion of the possible need for a sweeping flow of air or steam to dilute the produced oxygen in order to avoid possible materials and safety issues related to handling of pure oxygen at temperatures over $800^{\circ} \mathrm{C}$. From a thermodynamic efficiency standpoint, the use of a sweep gas improves the electrolyzer efficiency, but there are also some disadvantages associated with the use of an air sweep. First, dilution of the pure oxygen that is produced in the electrolysis stack with air would be wasteful since pure oxygen is a valuable commodity that could be sold as an electrolysis by-product. Second, production of a sweeping flow of high-pressure air at even a modest flow rate requires a significant amount of compressor power, compared to the electrolysis stack power consumption, which would seriously degrade the overall process efficiency, if a corresponding outlet turbo expander is not used. Finally, our research has indicated that pure oxygen can be safely handled at high temperature, if the right materials are used.

Overall syngas production efficiencies were also calculated for the no-sweep cases. These results are presented in Fig. 5. Efficiency values are plotted against current density in Fig. 5(a), against per-cell operating voltage in Fig. 5(b), and against syngas production rate in Fig. 5(c). Again, four cases are presented: low and high ASR, adiabatic and isothermal electrolyzer operation. Results of the no-sweep cases are qualitatively similar to the air-sweep cases, but efficiency values for the no-sweep cases are about 1.0 to 1.5 percentage points higher than for the corresponding air-sweep cases. Again, the overall process efficiencies collapse onto a single line when plotted as a function of per-cell operating voltage. The highest overall efficiency plotted in Fig. 5 (for ASR $=0.25$, isothermal, $i=0.0625 \mathrm{~A} / \mathrm{cm}^{2}$ ) is fully $1.5 \%$ higher than the power cycle efficiency of $48.3 \%$.

The results presented in Figs. 4 and 5 show the variation in overall syngas production efficiency as a function of electrolyzer current density and operating voltage for a fixed value $(88.9 \%)$ of steam $/ \mathrm{CO}_{2}$ utilization. In order to maintain a fixed value of steam/ $\mathrm{CO}_{2}$ utilization, the inlet flow rate of process gas was adjusted in proportion to the electrolyzer current density for each case. Alternately, the inlet process gas mass flow rate can be fixed at the maximum 
value and the effect of electrolyzer current density on overall syngas production efficiency can be calculated for the fixedmass-flow, variable-utilization case. For this case, steam $/ \mathrm{CO}_{2}$ utilization is proportional to the current density. Consequently at low current density (and low utilization), there is a significant excess of process gas flowing through the system. Handling of this excess process gas results in low overall syngas production efficiencies, as shown in Fig. 6. Results of four cases are shown: low-ASR, isothermal and adiabatic, and high- $A S R$, isothermal and adiabatic, all with air sweep. In Fig. 6(a), overall syngas production efficiencies are plotted as a function of current density. For the low-ASR cases, overall efficiencies range from about $20 \%$ at the lowest current density to $43 \%$ at the highest. The corresponding range for the high-ASR cases is $37 \%$ to $43 \%$. Again, the maximum current density for the low-ASR case is $1.0 \mathrm{~A} / \mathrm{cm}^{2}$ and $0.25 \mathrm{~A} / \mathrm{cm} 2$ for the high-ASR case. Note that the overall efficiency at the highest current densities, $43 \%$, is the same value as was plotted in Fig. 4 at the highest current densities. In fact these represent the same cases.

Fig. 6(b) shows the overall syngas production efficiencies for the variableutilization cases plotted as a function of percell operating voltage. In contrast to the fixed-utilization results (Fig. 4(b)), the variable-utilization efficiencies do not collapse onto a single line when plotted versus operating voltage.

The overall efficiency results for the variable-utilization case nearly collapse onto a single curve when plotted versus utilization, as shown in Fig. 6(c). This plot indicates a strong dependence on utilization, with overall efficiencies of only $20 \%$ at the lowest utilization values shown ( $5.7 \%)$, increasing to a maximum value of $43 \%$ at the highest utilization value considered (90\%). Again, low utilization results in relatively high irreversibilities associated

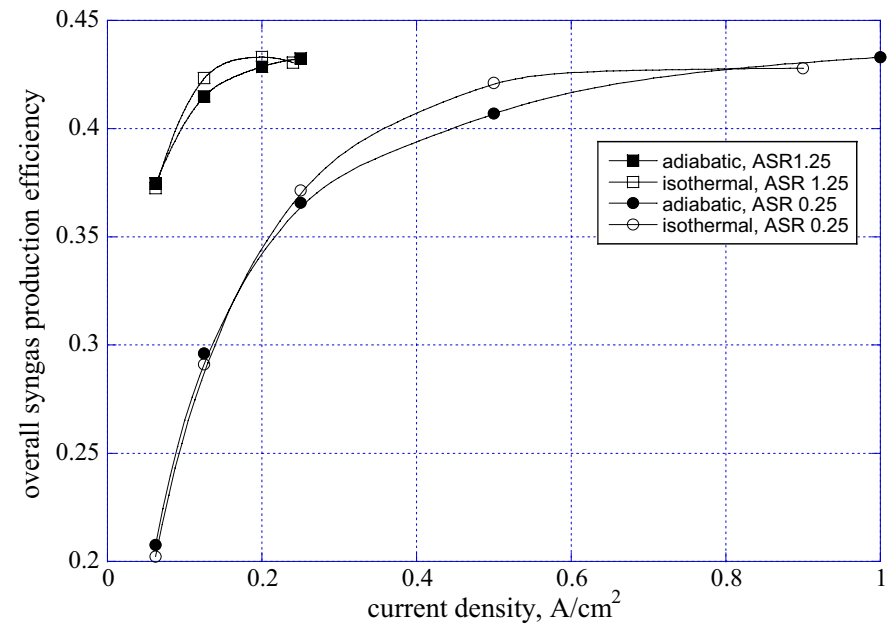

(a)

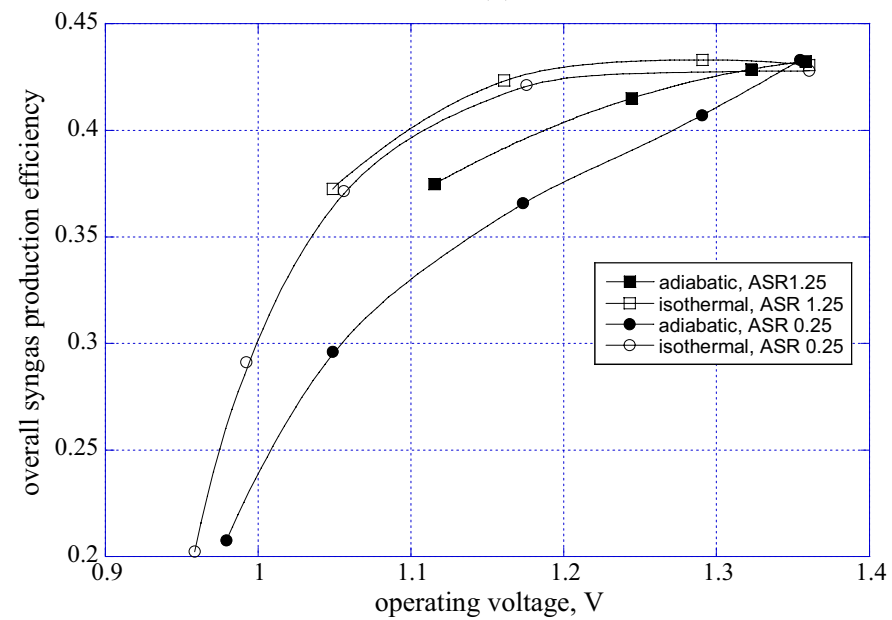

(b)

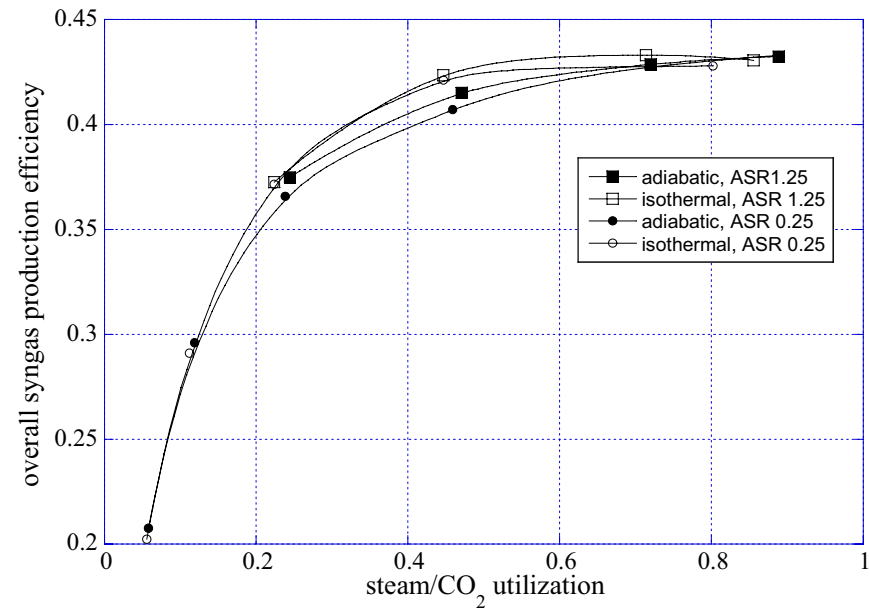

(c)

Figure 6. Overall syngas production efficiency for a fixed electrolyzer inlet flow rate with air sweep, plotted as a function of electrolyzer current density (a), as a function of electrolyzer operating voltage (b), and as a function of steam/ $\mathrm{CO}_{2}$ utilization (c). 
with incomplete heat recuperation, pumping and compression of excess process streams, etc.

The influence of reactor outlet temperature on power cycle and overall thermal-to-syngas process efficiencies is presented in Fig. 7. The process conditions for these simulations were described in the previous section. The upper curve in the plot is the power cycle thermal efficiency and the lower curve is the overall syngas production efficiency. The results indicate the importance of utilizing a high temperature heat source for improved process efficiency. The overall syngas production efficiencies for the thermal-neutral operating point are $3-5 \%$ lower than the power cycle efficiencies. The results indicate a $46 \%$ improvement in

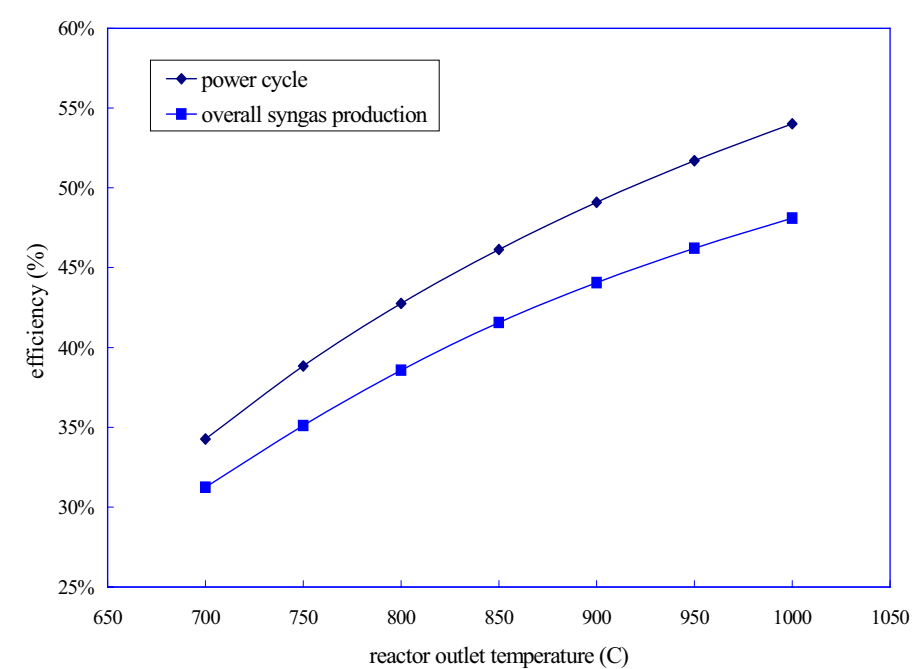

Figure 7. Power cycle and overall syngas production efficiencies at thermal-neutral voltage as a function of reactor outlet temperature. overall process efficiency at $1000^{\circ} \mathrm{C}$ compared to at a $700^{\circ} \mathrm{C}$ reactor outlet temperature.

\section{CONCLUSIONS}

An engineering process model has been developed for performance evaluation of a largescale syngas production plant based on high-temperature co-electrolysis of carbon dioxide and steam. Based on the results presented in this paper, the process appears to represent a promising technology for efficient production of syngas from nuclear energy. Overall thermalto-syngas process efficiencies of $43-48 \%$ were predicted with realistic modeling assumptions, including realistic treatment of heat exchanger performance. Higher process efficiencies result at higher reactor outlet temperatures due to increased power cycle efficiencies.

\section{ACKNOWLEDGMENTS}

This work was supported by the Idaho National Laboratory, Laboratory Directed Research and Development program and by the U.S. Department of Energy, Office of Nuclear Energy, Nuclear Hydrogen Initiative Program.

\section{COPYRIGHT STATEMENT}

This manuscript has been authored by Battelle Energy Alliance, LLC under Contract No. DE-AC07-05ID14517 with the U.S. Department of Energy. The United States Government retains and the publisher, by accepting the article for publication, acknowledges that the United States Government retains a nonexclusive, paid-up, irrevocable, world-wide license to publish or reproduce the published form of this manuscript, or allow others to do so, for United States Government purposes. 


\section{REFERENCES}

1. Herring, J. S., O'Brien, J. E., Stoots, C. M., and Hawkes, G. L., "Progress in HighTemperature Electrolysis for Hydrogen Production using Planar SOFC Technology," International Journal of Hydrogen Energy, Vol. 32, Issue 4, pp. 440-450, March 2007.

2. Forsberg, C. W., "The Hydrogen Economy is Coming. The Question is Where?" Chemical Engineering Progress, December, 2005, pp. 20-22.

3. Finan, A. E., Miu, K., and Kadak, A. C., "Nuclear Technology and Canadian Oil Sands; Integration of Nuclear Power with In-Situ Oil Extraction," Proceedings, 2006 International Congress on Advances in Nuclear Power Plants, ICAPP06, 2006, pp. 2329-2338.

4. O'Brien, J. E., Stoots, C. M., and Hawkes, G. L., "Comparison of a One-Dimensional Model of a High-Temperature Solid-Oxide Electrolysis Stack with CFD and Experimental Results," 2005 ASME International Mechanical Engineering Congress and Exposition, Nov. 5 - 11, Orlando.

5. O'Brien, J. E., McKellar, M. G., Hawkes, G. L., and Stoots, C. M., "Development and Validation of a One-Dimensional Co-electrolysis Model for Use in Large-Scale Process Modeling Analysis," Presented at the ASME 5th International Conference on Fuel Cell Science, Engineering, and Technology, June 18 - 20, 2007, New York, NY; submitted to the Journal of Fuel Cell Science and Technology.

6. Stoots, C. M., O'Brien, J. E., McKellar, M. G., Hawkes, G. L., and Herring, J. S., "Engineering Process Model for High-Temperature Steam Electrolysis System Performance Evaluation," AIChE 2005 Annual Meeting, Cincinnati, Oct. 30 - Nov. 4, 2005.

7. Hawkes, G.L., O'Brien, J.E., Stoots, C.M., Herring, S.J., and Hartvigsen, J., "3D CFD Model of High Temperature $\mathrm{H} 2 \mathrm{O} / \mathrm{CO} 2$ Co-Electrolysis," ANS Embedded Topical: International Topical Meeting on the Safety and Technology of Nuclear Hydrogen Production, Control, and Management, June 24 - 28, 2007, Boston, Massachusetts, USA.

8. LaBar, M. P., "The Gas Turbine-Modular Helium Reactor: A Promising Option for Near Term Deployment," General Atomics Report GA-A23952, April, 2002. 